\title{
Validation of vulnerability markers of dysfunctions in the socioemotional development of infants
}

\author{
Daniel Ignacio da Silva ${ }^{1}$ \\ Débora Falleiros de Mello² \\ Renata Ferreira Takahashi ${ }^{3}$ \\ Cody Stonewall Hollist ${ }^{4}$ \\ Verônica de Azevedo Mazza ${ }^{5}$ \\ Maria de La Ó Ramallo Veríssimo³
}

\begin{abstract}
Objectives: to validate the vulnerability markers of dysfunctions in the socioemotional development of infants. Methods: study with a sequential exploratory mixed-method design. The vulnerability markers elaborated in the qualitative phase were analyzed by experts in the quantitative phase using the Delphi technique with a minimum consensus of $70 \%$. Seventeen judges answered the questionnaire in the first round of analysis and 11 answered in the second round. Results: in the first round, two markers did not reach minimum consensus: the presence of instability in family relationships (66\%) and delinquency and/or drug abuse by parents/caregivers (65\%). In the second round, all markers were validated, with more than $90 \%$ agreement in most of the attributes, and reached the minimum consensus of $73 \%$. Conclusion: the eight vulnerability markers reached the minimum consensus for validation, and a relevant instrument for infant care can be developed after assessing the reliability and clinically validating these markers.
\end{abstract}

Descriptors: Health Vulnerability; Infant; Child Development; Developmental Disabilities; Development Disorders, Pervasive; Pediatric Nursing.

\footnotetext{
* Paper extracted from doctoral dissertation, "Validation of vulnerability markers of infants to dysfunctions in their socioemotional development", presented to Escola de Enfermagem, Universidade de São Paulo, São Paulo, SP, Brazil.

1 Universidade de Santo Amaro, São Paulo, SP, Brazil.

2 Universidade de São Paulo, Escola de Enfermagem de Ribeirão Preto, PAHO/WHO Collaborating Centre for Nursing Research Development, Ribeirão Preto, SP, Brazil.

3 Universidade de São Paulo, Escola de Enfermagem, São Paulo, SP, Brazil.

${ }^{4}$ University of Nebraska-Lincoln, College of Education and Human Sciences, Lincoln, NE, United States of America.

${ }^{5}$ Universidade Federal do Paraná, Departamento de Enfermagem , Curitiba, PR, Brazil.
}

\section{How to cite this article}

Silva DI, Mello DF, Takahashi RF, Hollist CS, Mazza VA, Veríssimo MLOR. Validation of vulnerability markers of dysfunctions in the socioemotional development of infants. Rev. Latino-Am. Enfermagem. 2018;26:e3087. [Access ]; Available in: DOI: http://dx.doi.org/10.1590/1518-8345.2736.3087. 


\section{Introduction}

The objective of this study was to validate the vulnerability markers of dysfunctions in the socioemotional development of infants. We attempted to construct an instrument that assessed dysfunctions in socioemotional development, which is determined by the maintenance or changes in social and emotional characteristics of children ${ }^{(1)}$ and characterized by the expression of emotions in social contexts, in the social triggers of emotional expressions, and in the social construction of emotional experience and understanding(2).

Socioemotional development is related to the development of the brain and the interactions or proximal processes experienced by the child from birth ${ }^{(1)}$ and can be analyzed by evaluating developmental milestones from several domains, including attachment, social competence, emotional competence, and selfperception $^{(3)}$.

The bioecological model of human development indicates that a child living in adverse conditions and in a disorganized environment is susceptible to developmental dysfunctions, including "recurrent difficulties in maintaining emotional control and integrating behavior in different developmental situations and domains"(1). Therefore, child development is affected by biological and contextual factors ${ }^{(4-5)}$.

Developmental dysfunctions include a group of diseases characterized by intellectual, physical, and social-emotional problems ${ }^{(6)}$. These dysfunctions are related to brain disorders caused by genetic changes or lesions in the central nervous system, exposure to teratogenic agents, trauma, infections, severe nutritional deficiency, and neonatal hypoxia or ischemia(6). Studies have confirmed that sociocultural, socioeconomic, psychosocial, and biological factors affect child development in all its dimensions, including socioemotional(4,7).

The technologies available to monitor child development include scales based on markers and expected behaviors for different age groups. These technologies assess the child's abilities but do not consider the factors that affect child development, leaving a significant gap in the analysis of dangerous situations.

The complexity of socioemotional development involves the concept of vulnerability, which is a set of conditions that make the child more susceptible to developmental dysfunctions due to the effect of individual, social, and programmatic dimensions ${ }^{(8)}$. The concept of vulnerability demands the proposition of interventions based on health needs, development of social responses, autonomy in care, preservation of health, and integrality and equity of health actions ${ }^{(9)}$

The need to instrumentalize health professionals to identify vulnerabilities in child development led to the proposition of the following question: How can professionals assess the vulnerability to dysfunctions in the socioemotional development of infants?

The construction of markers may help health professionals apply the concept of vulnerability as an indicator of qualitative aspects of the health-disease process at the individual and community levels, and these markers allow proposing interventions that address social responses to dysfunctions ${ }^{(9-10)}$. The term "vulnerability marker" includes the interaction of subjective and contextual attributes in the healthdisease process as social and historical phenomena(11).

This study assumes that the use of markers as health technologies, based on vulnerability elements, can improve care and socioemotional development by strengthening proximal processes, which are the specific forms of interaction between children and their environment ${ }^{(1)}$.

The identification of these elements and characterization of the conditions of child development beyond the short-term performance, expressed in behaviors or developmental milestones, requires the inclusion and organization of these elements in an instrument applicable to the care practice. Therefore, the objective of this study was to validate markers of vulnerability to dysfunctions in the socioemotional development of infants.

\section{Method}

This mixed-method study combined qualitative and quantitative methods(12). A sequential exploratory design was used, including a first (qualitative) phase for marker construction and a second (quantitative) phase for content validation.

Vulnerability markers were elaborated in the qualitative phase. These markers are thematic categories of exposure factors that affect the socioemotional development of infants ${ }^{(13)}$ and are theoretically based on the context dimensions of the bioecological model of human development-microsystem, mesosystem, exosystem, and macrosystem ${ }^{(1)}$-and the Child Vulnerability Matrix for situations that jeopardize child development in the individual, social, and programmatic dimensions ${ }^{(8)}$. In this study, infants are children younger than two years. 
Each marker is composed of a title, components, and an operational manual, and the function of the latter is to guide the application of the analytical instrument. The manual contains the definition of the markers, vulnerabilities, sources of information on the marker, and the criteria for defining the presence of the marker ${ }^{(11)}$.

The original version of the vulnerability markers was sent to the experts for content validation. The markers are shown in Figures 1 and 2.
The Delphi technique ${ }^{(14)}$ was applied in the quantitative phase to validate the content of the markers, components, and operational manuals by researchers identified in the Platform Lattes who were specialists in socioemotional development. The selection criteria of the judges were the time of clinical experience and/or research on infant health, completion of undergraduate studies with a minimum duration of 5 years, and graduate studies in infant health.

Difficulty of parents/caregivers in bonding with the child

Do parents/caregivers have difficulty interacting or do not interact with the child? (Evaluate activities related to play, reading, and learning.) Has the child been pre-weaned from exclusive breastfeeding? (Confirm whether the child was breastfed and/or was weaned before six months. If not breastfed, consider this element of vulnerability).

Do parents/caregivers respond aggressively and/or unfriendly to the child? (Use of an aggressive or loud tone of voice, aggressive physical expressions, or physically manipulate the child.)

Do parents/caregivers overprotect the child? (They anticipate actions to the speech of the child, giving what the child wants before she asks.)

Do parents/caregivers present anxiety (worry and fears) in the face of behavioral difficulties (anxiety, hyperactivity, or aggressiveness) presented by the child?

Do parents/caregivers have behaviors related to child rejection? (Presence of non-acceptance of the child, lack of care, perception of the child as problematic, or non-acceptance of the pregnancy by the mother.)

Limitations of parents/caregivers in providing physical protection and safety to the child

Are there signs of violence and abuse against the child? (Signs of alertness, including shyness, withdrawal, isolation, depression, panic, poor school performance, and presence of injuries.)

Do parents/caregivers neglect child protection measures against accidents? (Occurrence of falls, burns, and electric shocks.)

Are there parental neglect behaviors with the child? (Signs of rash, poor hygiene, and/or malnutrition in the child.)

Did the mother perform prenatal examination? (Non-attendance to consultations.)

Presence of illnesses in parents/caregivers

Are there signs and symptoms of depression and/or stress in parents/caregivers?

Are there signs of depression and/or stress in the mother in the prenatal and/or puerperal period?

Are there signs and symptoms of schizophrenia and other mental disorders in parents/caregivers?

Are there signs and symptoms of anxiety disorders in parents/caregivers?

Are there signs and symptoms of compulsive disorders such as eating disorders (bulimia or anorexia) in parents/caregivers? Did the mother present with iron deficiency during prenatal care?

\section{Presence of instability in family relations}

Has the child witnessed the separation of her parents/caregivers?

Has there been family instability in the child's environment? (Marital conflicts, change of residence, change of caregiver and/or presence of other family members in the house.)

Does the child live in a single-parent family? (The mother lives without a partner, and the father is absent from the family unit).

Is there childcare support when the mother works outside? (Check whether family and social support is available).

Do parents/caregivers stop caring for the child because of negative experiences? [Presence of child prematurity, stress, family suffering,

and imminence of death or death (natural or accidental) of a family member.]

\section{Delinquency and/or drug abuse by parents/caregivers}

Are parents/caretakers arrested or in custody?

Do parents/caregivers manifest criminal/delinquent behaviors (involvement in robbery, drug trafficking, or murders)?

Is there domestic violence against parents/caregivers?

Do parents/caregivers use illicit drugs?

Figure 1. Original version of the vulnerability markers and their components related to the bioecology of development and individual vulnerability. São Paulo, Brazil, 2016 


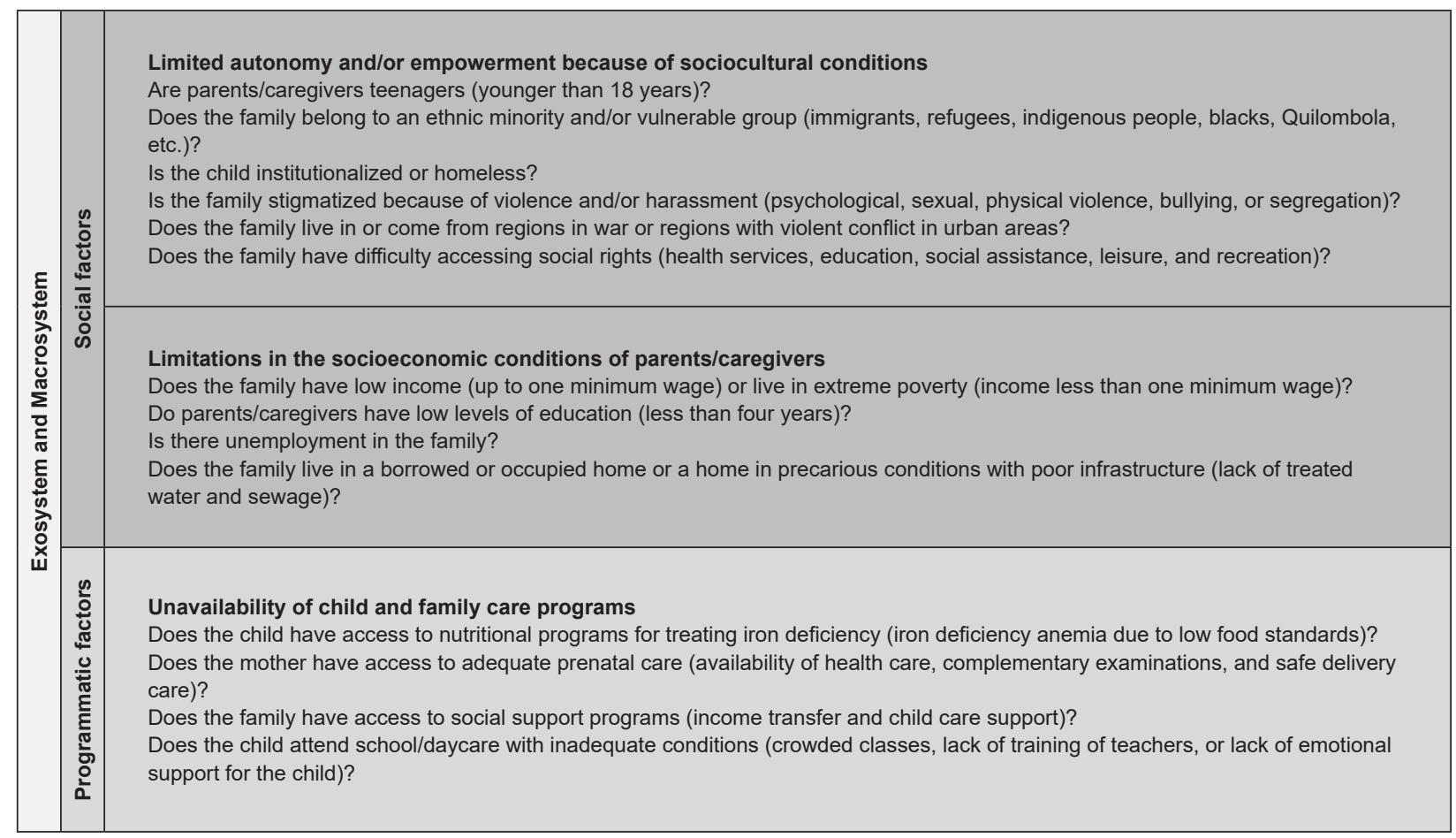

Figure 2. Original version of the vulnerability markers and their components related to the bioecology of development and social and programmatic vulnerability. São Paulo, Brazil, 2016

Eighty-four nursing researchers and other health professionals were invited to assess the instrument because the concept of vulnerability is multidisciplinary. The invitations were made by sending an e-mail containing the Informed Consent Form (ICF) and the validation script of the markers in electronic format. Participants were considered the professionals who returned the ICF and completed the questionnaire within the deadline established for the first round. Two rounds of evaluation were necessary to reach the minimum consensus.

The questionnaire was developed using Microsoft Excel. The first page contained the ICF and guidelines for completing the questionnaire. All the content related to the markers was described in a spreadsheet, allowing participants to answer the questions using all available information.

The criteria used during validation to evaluate the attributes and relevance of the markers were simplicity, clarity, pertinence, and precision. The questions asked were 1 . "Is the marker easily explained and understood?", 2. "Can data on the marker be easily obtained?", 3. "Does the marker effectively identify vulnerabilities to dysfunctions in the socioemotional development of infants?", 4. "Can the marker be used in care practice?", 5. "How important is this marker to identify infant vulnerabilities?"

The following questions were formulated to evaluate the attributes of marker components: 1 . "Does the component adequately express the presence of a vulnerability in infants?", 2 . "Is the component constructed with simple and unambiguous expressions?", 3. "Does the component differ from other components?"

The following questions were formulated to evaluate the operational manual: 1 . "Was the marker and what it measures adequately described?", 2. "This marker reflects vulnerabilities in individual, social, or programmatic factors. Do you agree with this statement?", 3. "Are the sources of information accessible and adequate to obtain the data?", 4. "Are the criteria adequately described and allow the same interpretation among the different health professionals who used the instrument?"

Only the "yes/agree" question was considered, excluding from the analysis the answers "yes, but requires revision/partial agreement" and "no/disagree." The revisions necessary between each collection stage were made according to the suggestions of the judges.

Possible answers were agreement, partial agreement, or disagreement, and there was room for comments. Descriptive statistics were used for data analysis, and the minimum consensus was $70 \%{ }^{(15-}$ 16). The consensus is the expected result of the Delphi technique. Therefore, the definition of consensus criteria and the description of the degree of agreement and the validation results are essential(15-16).

This study was approved by the Research Ethics Committee of the School of Nursing of the University of São Paulo via the Certificate for Ethics Assessment (Certificado de Apresentação para Apreciação ÉticaCAAE) No. 57933816.8.0000.5392. The study complied with human research guidelines. 


\section{Results}

The first round of content validation was completed by 17 participants. Of these, 11 were nurses, two were physical therapists, two were occupational therapists, and two were psychologists. Most participants had a time of academic education longer than 10 years, with an M.S. and/or Ph.D. degree and experience in teaching, research, and care practice.

The judges returned the materials within 30 days and completed $95 \%$ of the questionnaires in the first round. The results of the assessments were tabulated according to pre-established parameters. The level of consensus of the judges in the first round is presented in Table 1.

Table 1. Minimum level of consensus of the judges in the first round of content validation. São Paulo, Brazil, 2017

\begin{tabular}{lcc}
\hline Marker & \multicolumn{2}{c}{ Minimum level of consensus (\%) } \\
\cline { 2 - 3 } $\begin{array}{l}\text { Difficulty of parents/caregivers in bonding with the child } \\
\text { Limitation of parents/caregivers in providing physical protection and } \\
\text { safety to the child }\end{array}$ & $\begin{array}{c}\text { Attributes and } \\
\text { marker relevance }\end{array}$ & 75.0 \\
Presence of illnesses in parents/caregivers & 93.0 & 81.0 \\
Presence of instability in family relations & 94.0 & 73.0 \\
Delinquency and/or drug abuse by parents/caregivers & 88.0 & 73.0 \\
Limited autonomy and/or empowerment because of sociocultural & 94.0 & 87.0 \\
conditions & 81.0 & 64.0 \\
Poor socioeconomic conditions of parents/caregivers & 81.0 & 86.0 \\
Unavailability of child and family care programs & 93.0 & 65.0 \\
\hline
\end{tabular}

In the first round, the level of consensus of most of the assessed items was medium to high (70-94\%). In addition to the objective answers, the judges provided 206 written suggestions, which were used in content review in the second round. The judges' suggestions were related to the writing, presentation, and exemplification of the components.

The fourth marker component, "difficulty of parents/caregivers in bonding with the child," was modified according to the judges' recommendation: The term "parental anxiety" does not seem to be the most appropriate. My interpretation is that this term indicates the exaggerated concern, maladjustment, or emotional imbalance of the parents due to the behavior of the child. (J10)

The second and third marker components, "limitations of parents/caregivers in providing physical protection and safety to the child," were drafted differently without the term "neglect" considering the following recommendation: I suggest replacing the term "neglect" with another construct, such as "do not take the necessary measures." This marker is important because it is common for families not to identify the risk factors for accidents. (J10) The fourth component was rewritten according to the judge's suggestion: I suggest replacing the term "adherence" with "undergoing prenatal examination and prenatal care." (J10)

The number of components of the marker "presence of illnesses in parents/caregivers." was reduced from six to three considering the recommendation: All questions except the last one were related to mental health. However, does altered physical health affect childcare? In addition, considering that all these symptoms are related to changes in mental health, it may seem confusing: can stress, depression, and schizophrenia affect care in different ways? If so, why are these symptoms separated? (J15)

The simplicity and expression of the fourth marker component, "presence of instability in family relations," reached a consensus of $64 \%$, which is lower than the minimum consensus. The component was changed according to the following commentary: I suggest the following change: "(..) negative experiences within the family." (J1) Describe the term "negative experiences" better and remove the terms related to mental health problems because they have already been included in another marker. (J15)

It was suggested to include support for mothers in this marker: I suggest leaving this item as "there is no support for childcare" and exclude the sentence "for the mother who works outside" because I consider that support is necessary for all mothers, regardless of working outside. (J13) Therefore, the term "social support" was added.

The relevance of the first, third, and fourth components of the marker "delinquency and/or abuse by parents/caregiver" reached a consensus of $64 \%$. The simplicity and expression of these components reached a consensus of $65 \%$. The judges made the following suggestion: Fulfillment of sentence because of 
the practice of criminal offenses. The inconsistency is related to the verb in the two tenses (present and past). (J15) Does this item indicate that caregivers suffer from domestic violence or the male partner is violent with the female partner? (J4) Review "there is presence." I suggest including the question "Do parents/caregivers make use of psychoactive or other drugs?" (J9)

With respect to the marker "limited autonomy and/or empowerment because of sociocultural conditions," the following suggestion was accepted: Is the difficulty related to the parents or the child? Autonomy/ empowerment is also a limitation. I suggest leaving only the term "autonomy" (J15). The fifth component of this marker was modified according to the judges' recommendation: I suggest adding "gangs or organized crime" to a situation closer to the "Brazilian war conflicts. " (J1) I suggest excluding the term "war" because it is not the reality of Brazil, and perhaps include the term "urban violence." (J13)

The first marker component, "poor socioeconomic conditions of parents/caregivers," was modified according to the judges' recommendation: The question is repetitive. I suggest including the question: "Does the family have an income lower than the minimum wage"? (J11)
I suggest rewriting the sentence, perhaps expressing the item as per capita income because a family with three members living on a minimum wage is different from a family with ten people living on a minimum wage. (J13) The fourth component was modified according to the suggestions of one judge: Can the family live in a borrowed or occupied house under normal conditions? I think what matters is the precarious situation. I suggest eliminating the first part of the sentence and including the sentence "The family lives in a precarious house." (J15)

After the inclusions and adaptations in the first round, the instrument was subjected to the second round of the Delphi technique. Of the 17 judges who participated in the first round, 11 participated in the second round. Of these, eight were nurses, one was a physiotherapist, and two were occupational therapists. The majority had a time of academic education longer than 10 years, with an M.S. and/or Ph.D. degree and experience in teaching, research, and care practice.

In the second round, the judges returned the materials within 30 days and completed $99 \%$ of the questionnaires. The level of consensus of the judges is presented in Table 2 .

Table 2. Minimum level of consensus of the judges in the second round of content validation. São Paulo, Brazil, 2017

\begin{tabular}{|c|c|c|c|}
\hline \multirow{2}{*}{ Marker } & \multicolumn{3}{|c|}{ Minimum level of consensus (\%) } \\
\hline & $\begin{array}{l}\text { Operating } \\
\text { manual }\end{array}$ & $\begin{array}{l}\text { Attributes and marker } \\
\text { relevance }\end{array}$ & $\begin{array}{l}\text { Attributes of marker } \\
\text { components }\end{array}$ \\
\hline Difficulty of parents/caregivers in bonding with the child & 91.0 & 91.0 & 73.0 \\
\hline $\begin{array}{l}\text { Limitation of parents/caregivers in providing physical protection } \\
\text { and safety to the child }\end{array}$ & 91.0 & 100.0 & 91.0 \\
\hline Presence of illnesses in parents/caregivers & 100.0 & 91.0 & 91.0 \\
\hline Instability in family relations and poor social support & 100.0 & 100.0 & 73.0 \\
\hline Violence and/or drug abuse by parents/caregivers & 91.0 & 100.0 & 91.0 \\
\hline $\begin{array}{l}\text { Limited autonomy of parents/caregivers because of } \\
\text { sociocultural conditions }\end{array}$ & 100.0 & 100.0 & 91.0 \\
\hline Poor socioeconomic conditions of parents/caregivers & 100.0 & 100.0 & 82.0 \\
\hline Unavailability of child and family care programs & 91.0 & 100.0 & 82.0 \\
\hline
\end{tabular}

The level of consensus of most of the elements evaluated in the second round was high (82-100\%), and two markers obtained the minimum consensus of $73 \%$, which was higher than the established minimum, and the validation process was complete. In the last round, the judges sent 45 comments with suggestions on the writing of the components, and these suggestions improved the clarity and understanding of the instrument.
The markers of vulnerability to dysfunctions in the socioemotional development of infants and marker components of the final version are described in Figure 3. These elements were classified into three categories according to the contexts of the bioecological model of human development and vulnerability dimensions: individual (green), social (orange), and programmatic (blue). 


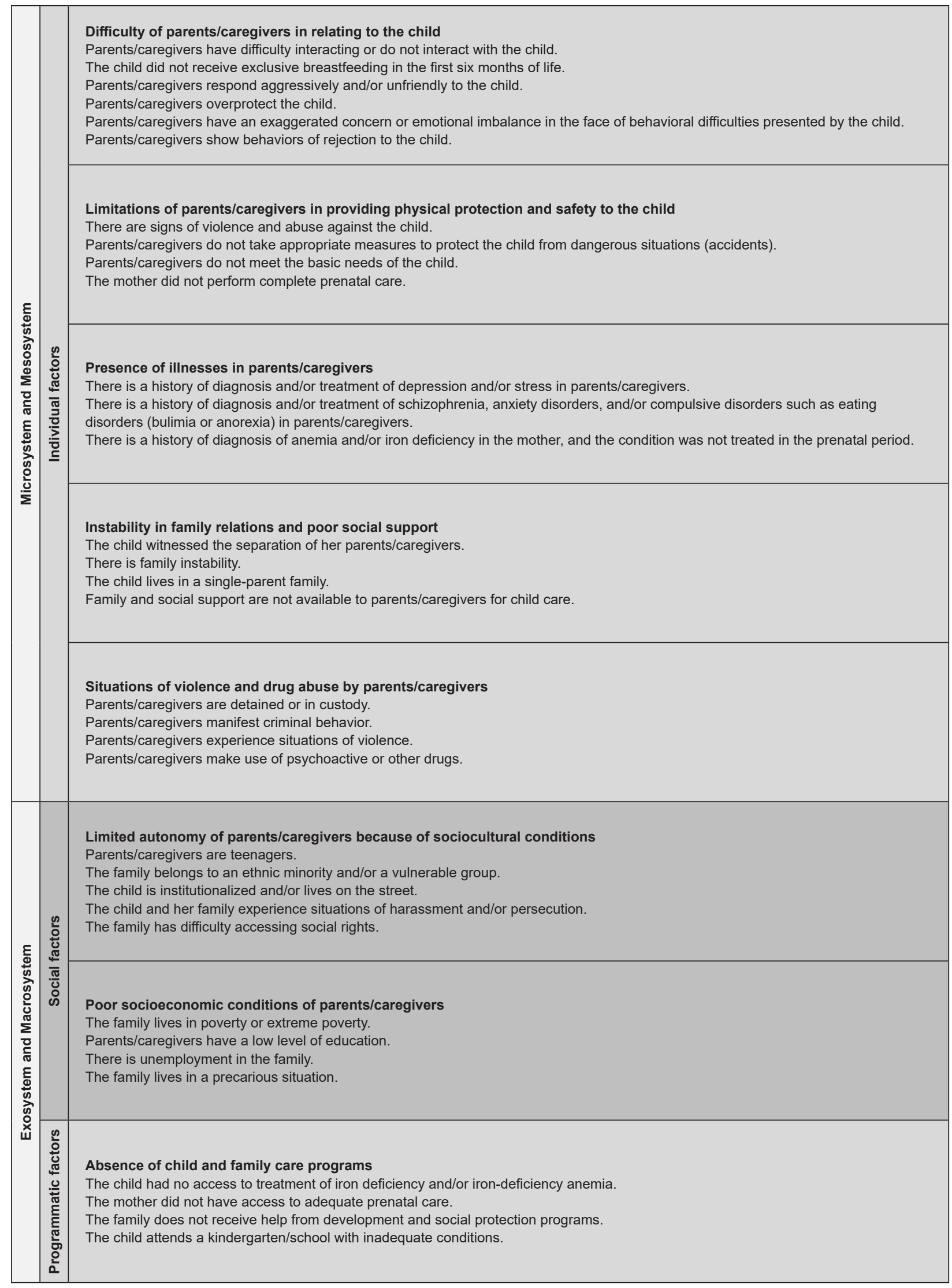

Figure 3. Final version of vulnerability markers and their components after content validation. São Paulo, Brazil, 2017

\section{Discussion}

The vulnerability markers were subjected to the Delphi technique and assessed by qualified professionals (with an M.S. and/or Ph.D. degree) with more than 10 years of academic training. These judges performed a critical analysis of the material and provided many suggestions (206 in the first round and 45 in the 
second). The questionnaire adherence rate was high ( $95 \%$ in the first round and $99 \%$ in the second round). These results corroborate the Delphi technique, whose application demands the recruitment of experienced, socially critical, and professionally self-critical judges who can make significant changes and adaptations to the analyzed material(17-18).

The number of participants in the first and second rounds was considered pertinent by the literature, which defines a minimum of $10-15$ specialists to obtain a set of high-quality opinions ${ }^{(18)}$. Therefore, the markers were appraised by a diverse group of judges from different areas of practice, allowing a thorough analysis of the material.

Although this instrument was initially intended for use in the area of nursing in infant health, the evaluation and improvement of the quality of these parameters by psychologists, occupational therapists, and physical therapists were relevant considering that psychosocial development is multidisciplinary. This multiprofessional evaluation is recommended by the Delphi technique, which makes these parameters accessible to a diverse and geographically dispersed population, allowing the provision of different opinions ${ }^{(19)}$.

Failure to reach the expected consensus in the first round for all analyzed items may be justified by the high number of comments from the judges because many sentences were written using terms deemed inappropriate. The achievement of a minimum consensus of $73 \%$ and the comparatively lower number of comments in the second round demonstrated that the material was more appropriate.

With regard to changes in the content of the marker components "difficulty of parents/caregivers in bonding with the child" and "limitations of parents/caregivers to provide physical protection and safety to the child," the modifications allowed a better understanding of the limitations of childcare. These limitations affect the type and quality of care and the interactions between parents and infants ${ }^{(1,20)}$.

With respect to the marker "illnesses in parents/ caregivers," the judge's recommendation to include the mental health conditions to facilitate their identification by professionals was considered adequate. The presence of mental disorders is related to the lower degree of affection for the infant and the development of weak bonding(20).

With respect to the marker "presence of instability in family relations," which did not reach the minimum consensus, the judges' suggestions were pertinent because negative experiences might lead to vulnerabilities in caregivers, limit childcare support, and lead to neglect and exposure of the child to dangerous situations ${ }^{(21-22)}$.

With regard to the marker "situations of delinquency and/or drug abuse by parents/caregivers," which also did not reach minimum consensus, addressing the drug abuse of parents/caregivers is relevant to identify situations that are adverse to the socioemotional development of the infant(23-24). Similarly, home violence suffered by caregivers may impair childcare and consequently the bonding with the child ${ }^{(25)}$. Therefore, the proposed modifications avoid erroneous interpretations of professionals when using this instrument.

With regard to the marker "limited autonomy of parents/caregivers because of sociocultural conditions," emphasizing the autonomy of caregivers in the title of the marker is relevant because this marker reflects the caregivers' ability to care for the child(8,22-23). Adaptations were made in the component of this marker to characterize violence as a set of conditions that imposed stigma and oppression on caregivers ${ }^{(23)}$.

The changes in the marker "poor socioeconomic conditions of parents/caregivers" are pertinent because professionals should understand that growth under conditions of poverty exposes the child to poor living conditions. Therefore, the socioeconomic status of the family directly affects childcare ${ }^{(4,8)}$.

The high agreement rates for vulnerability markers starting in the first round of analysis indicate that such markers are comprehensive for the bioecology of development $^{(1)}$ and vulnerability ${ }^{(8)}$.

The reliability and clinical validation of the vulnerability markers presented in this study need to be assessed beyond the consensus of expert opinions, and this validation will increase the applicability of primary health care practices to promote the socioemotional development of infants ${ }^{(8)}$.

\section{Conclusion}

The markers of vulnerability to dysfunctions in the socioemotional development of infants was validated after two rounds of the Delphi technique, and most markers, components, and operational manuals reached a high rate of agreement ( $>90 \%$ ) and a minimum level of consensus of $73 \%$.

The consensus reached using the Delphi technique allows testing this technology in clinical practice to assess its reliability by professionals to create care models based on the actual health needs of infants and minimize exposure factors and the vulnerability to dysfunctions in socioemotional development. 
One of the limitations of this study was that the markers were based on scientific evidence that might not account for the totality of current vulnerability situations; therefore, the reliability of these markers needs to be evaluated. Longitudinal studies that allow the routine clinical validation of vulnerability markers by health professionals during child and family care are necessary.

For nursing practice, the application of this instrument allows constructing a scale of vulnerability, identify new diagnoses in nursing, and elaborate intervention plans that promote the socioemotional development of infants by nurses and other professionals.

\section{Referências}

1. Bronfenbrenner U, Evans GW. Developmental science in the 21st century: Emerging questions, theoretical models, research designs and empirical findings. Soc Dev. [Internet]. 2000 [cited Apr 20, 2017]; 9(1):115-25. Available from: http://onlinelibrary.wiley. com/ doi/10.1111/1467-9507.00114/abstract

2. Thompson RA. Doing it with feeling: The emotion in early socioemotional development. Emot Rev. [Internet]. 2015 [cited Apr 22, 2017]; $7(1): 121-5$. Available from: http://journals.sagepub. com/ doi/abs/10.1177/1754073914554777

3. Campbell S, Denham S, Howarth G, Jones S, Whittaker J, Williford A et al. Commentary on the review of measures of early childhood social and emotional development: Conceptualization, critique, and recommendations. J Appl Dev Psychol. [Internet]. 2016 [cited Apr 23, 2017];45:19-41. Available from: https://www.sciencedirect.com/science/article/pii/ S0193397316300028

4. Richter L, Daelmans B, Lombardi J, Heymann J, Boo $F$, Behrman J et al. Investing in the foundation of sustainable development: pathways to scale up for early childhood development. The Lancet [Internet]. 2017 [cited Jan 23, 2018]; 389(10064):103-18. Available from: http://www.thelancet.com/journals/lancet/ article/PIIS0140-6736(16)31698-1/abstract

5. Shonkoff JP. Rethinking the Definition of EvidenceBased Interventions to Promote Early Childhood Development. Pediatrics. [Internet]. 2017 [cited Jan 23, 2018]; 140(6):e20173136. Available from: http://pediatrics.aappublications.org/content/ early/2017/11/10/peds.2017-3136

6. Moreno-De-Luca A, Myers SM, Challman TD, MorenoDe-Luca D, Evans DW, Ledbetter DH. Developmental brain dysfunction: Revival and expansion of old concepts based on new genetic evidence. Lancet Neurol. [Internet]. 2013 [cited Set 23, 2017]; 12(4):406-14. Available from: http://www.thelancet.com/journals/ laneur/article/PIIS1474-4422(13)70011-5/abstract 7. Ngure FM, Reid BM, Humphrey JH, Mbuya MN, Pelto G, Stoltzfus RJ. Water, sanitation, and hygiene (WASH), environmental enteropathy, nutrition, and early child development: making the links. Ann N Y Acad Sci. [Internet]. 2014 [cited Jun 3, 2018];1308:118-28. Available from: http://journals.sagepub.com/ doi/abs/10.1177/15648265150361S113

8. Silva DI, Chiesa AM, Veríssimo MLOR, Mazza VA. Vulnerability of children in adverse situations to their development: proposed analytical matrix. Rev Esc Enferm USP. [Internet]. 2013 [cited Nov 11, 2017]; 47(6):1397-402. Available from: http://dx.doi.org/ 10.1590/S0080-623420130000600021

9. Silva DI, Mello DF, Takahashi RF, Veríssimo MLOR. Children's vulnerability to health damages: elements, applicability and perspectives. IOSR-JNHS. [Internet]. 2016 [cited Jun 02, 2018]; 5(5):15-20. Available from: http://www.iosrjournals.org/iosr-jnhs/papers/vol5issue5/Version-3/D0505031520.pdf

10. Souza SNDHD, Mello DF, Ayres JRCM. Breastfeeding from the perspective of programmatic vulnerability and care. Cad Saúde Pública. [Internet]. 2013 [cited Jun 2, 2018]; 29(6):1186-94. Avaliable from: https://www. scielosp.org/article/csp/2013.v29n6/1186-1194/

11. Guanilo MCTU, Takahashi RFT, Bertolozzi MR. Assessing the vulnerability of women to sexually transmitted diseases STDS/ HIV: construction and validation of markers. Rev Esc Enferm USP. [Internet]. 2014 [cited Sep 12, 2017]; 48(Esp):156-63. Available from: http://dx.doi.org/10.1590/S0080-623420140000600022 12. Johnson RB, Onwuegbuzie AJ. Mixed Methods Research: A Research Paradigm Whose Time Has Come. Educ Res. [Internet]. 2004 [cited Sep 18, 2017];33(7):14-26. Available from: http://journals. sagepub.com/doi/abs/10.3102/0013189X033007014

13. Silva DI, Mello DF, Mazza VA, Toriyama ATM, Veríssimo MLOR. Dysfunctions in the socioemotional development of infants and its related factors: an integrative review. Texto Contexto Enferm. In press 2018.

14. Kezar A, Maxey D. The Delphi technique: an untapped approach of participatory research. Int J Soc Res Method. [Internet]. 2016 [cited Jun 2, 2018];19:14360. Available from:https://www.tandfonline.com/doi/fu Il/10.1080/13645579.2014.936737

15. Slade SC, Dionne CE, Underwood M, Buchbinder $R$, Beck B, Bennell $K$, et al. Consensus on exercise reporting template (CERT): modified Delphi study. Phys Ther. [Internet]. 2016 [cited Jun 9, 2018]; 
96(10):1514-24. Available from: https://academic.oup. com/ptj/article/96/10/1514/2870241

16. Diamond IR, Grant RC, Feldman BM, Pencharz PB, Ling SC, Moore AM, et al. Defining consensus: a systematic review recommends methodologic criteria for reporting of Delphi studies. J Clin Epidemiol. [Internet].2014 [cited Jun 2, 2018];67:401e9. Available from: http://dx.doi.org/10.1016/j.jclinepi.2013.12.002 17. Vieira MA, Ohara CVS, De Domenico EBL. The construction and validation of an instrument for the assessment of graduates of undergraduate nursing courses. Rev. Latino-Am. Enfermagem. [Internet] 2016 [cited Jun 4, 2018]; 24:e2710. 2015 [cited Sep 24, 2017]; Available from: http://dx.doi.org/10.1590/15188345.0834 .2710

18. Jacob E, Duffield C, Jacob D. A protocol for the development of a critical thinking assessment tool for nurses using a Delphi technique. J Adv Nurs. [Internet] 2017 [cited Jun 4, 2018]; 73(8):1982-8. Available from: http://dx.doi.org/10.1111/jan.13306.

19. Pessoa TRRF, Noro LRA. Pathways for graduation evaluation in Dentistry: logical model building and validation criteria. Cienc Saúde Coletiva. [Internet] 2015 [cited Jun 4, 2018]; 20(7):2277-90. Available from: https://www.scielosp.org/scielo.php?pid=S141381232015000702277\&script=sci_arttext

20. Pillhofer M, Spangler G, Bovenschen I, Kuenster A, Gabler S, Fallon B, et al. Pilot study of a program delivered within the regular service system in Germany: Effect of a short-term attachment-based intervention on maternal sensitivity in mothers at risk for child abuse and neglect. Child Abuse Negl. [Internet] 2015 [cited Jun 5, 2018];42:163-73. Available from: https://www.sciencedirect.com/science/article/abs/pii/ S0145213414002324

21. Muzik M, Rosenblum K, Alfafara E, Schuster M, Miller $\mathrm{N}$, Waddell R et al. Mom Power: preliminary outcomes of a group intervention to improve mental health and parenting among high-risk mothers. Arch Womens Ment Health. [Internet] 2015 [cited Jun 5, 2018];18(3):50721. Available from: https://link.springer.com/ article/10.1007/s00737-014-0490-z

22. Briggs R, Silver E, Krug L, Mason Z, Schrag R, Chinitz $S$, et al. Healthy Steps as a moderator: The impact of maternal trauma on child social-emotional development.
Clin Pract Pediatr Psychol. [Internet] 2014 [cited Jun 5, 2018];2(2):166-75. Available from: http://psycnet. apa.org/fulltext/2014-24042-003.html

23. Freeman PC. Prevalence and relationship between adverse childhood experiences and child behavior among young children. Infant Ment Health J. [Internet] 2014 [cited Jun 5, 2018];35(6):544-54. Available from: https://onlinelibrary.wiley.com/doi/full/10.1002/ imhj. 21460

24. Ranta J, Raitasalo K. Disorders of cognitive and emotional development in children of mothers with substance abuse and psychiatric disorders. Nord Stud Alcohol Dr. [Internet] 2015 [cited Jun 5, 2018];32(6):591-604. Available from: http://journals. sagepub.com/doi/abs/10.1515/nsad-2015-0056

25. Olusegun E. Domestic violence, risky family environment and children: A bio-psychology perspective. Int J Psychol Couns. [Internet] 2014 [cited Jun 5, 2018];6(8):107-18. Available from: http://www. academicjournals.org/journal/IJPC/article-full-text/ F86A3A447577 Creative Commons (CC BY).

This license lets others distribute, remix, tweak, and build upon your work, even commercially, as long as they credit you for the original creation. This is the most accommodating of licenses offered. Recommended for maximum dissemination and use of licensed materials. 